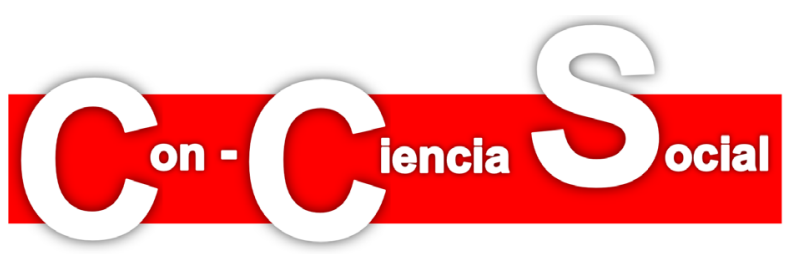

\title{
Lo que la historia global es y lo que debiera ser
}

\section{What global history is and what it should be}

\author{
Juan Seoane \\ I.E.S. Pirámide (Huesca) \\ j73seoane@gmail.com
}

Recibido en noviembre 2019

Aceptado en diciembre 2019

DOI:10.7203/con-cienciasocial.3.16794

\section{RESUMEN}

La globalización, como fenómeno histórico vinculado a la fase expansiva de la última gran revolución tecnológica, ha tenido, como otras globalizaciones históricas, un extraordinario impacto, no sólo en los ámbitos económico, social o político sino también en lo que a la epistemología de la Historia se refiere. La historia global es la adaptación de la Historia, como disciplina académica, al marco creado por la globalización. Como en otros períodos de globalización anteriores, los desequilibrios y dificultades acumulados durante las fases expansivas están dando paso a procesos desglobalizadores. ¿Qué enfoque debería proponer la disciplina histórica ante los últimos acontecimientos? ¿Es la historia global una herramienta útil? Seguiremos las propuestas y trabajos de varios autores en un intento de dar respuesta a estas preguntas y, también, en un intento de comprender mejor el encaje de la historia global en un momento de retroceso de la globalización.

Palabras clave: Globalización, desglobalización, historia global, marco conceptual, naturalización, régimen de verdad.

\begin{abstract}
Globalization, as a historical phenomenon connected to the expansive phase of the last great technological revolution, has had, like other historical globalizations, an extraordinary impact, not only in the economic, social or political spheres but also in reference to epistemology of history. Global history is the adaptation of history, as an academic discipline, to the framework created by globalization. As in other previous periods of globalization, the imbalances and difficulties accumulated during the expansive phases are giving way to dis-globalizing processes. What approach should historical discipline propose to the latest events? Is global history a useful tool? We will follow the proposals and works of several authors in attempt of giving answer to these questions and, also, in an attempt to better understand the fit of global history at a time of backward of globalization.
\end{abstract}

Keywords: Globalization, dis-globalization, global history, conceptual framework, naturalization, truth regime.

\section{Referencia}

Seoane, J. (2020). Lo que la historia global es y lo que debería ser. Con-Ciencia Social (segunda época), 3, 147-156. DOI:10.7203/con-cienciasocial.3.16794 
Sólo tiene importancia la determinación del régimen de veridicción que les permitió decir y afirmar como verdaderas una serie de cosas a cuyo respecto acertamos hoy a saber que quizá no lo fueran tanto. Tal es el aspecto, precisamente, en el que el análisis histórico puede tener un alcance político. Lo que políticamente tiene su importancia no es la historia de lo verdadero, no es la historia de lo falso, es la historia de la veridicción. (Foucault, 2009, p.47)

\section{¿QUÉ ES LA HISTORIA GLOBAL?}

¿Era la globalización un fenómeno histórico irreversible? ¿Era una buena idea orientar el enfoque de la disciplina histórica asumiendo esa presunta irreversibilidad?

Desde comienzos de la década de los noventa y hasta el inicio de la crisis económica en 2007 un coro de trabajos académicos, prensa económica y responsables políticos cantaba la idea de que la globalización era un fenómeno histórico no sólo deseable, sino inevitable. Resulta de fácil comprobación en cualquier hemeroteca observar hasta qué punto esta idea ser convirtió en una verdad incuestionable. En ese contexto se desarrolló toda una corriente de estudios centrados en lo que se denominó historia global. El trabajo de Sebastian Conrad (2017) resulta útil a la hora de poner el foco sobre esta corriente historiográfica y, también, sobre un conjunto de asuntos polémicos relacionados con la globalización y la historia global. Este libro intenta aclarar el concepto mismo de historia global y plantear algunas críticas necesarias al mismo.

La historia global, tal y como señala Conrad, se gestó y adquirió importancia en el ámbito anglosajón y es indisoluble del desarrollo de la globalización como fenómeno histórico. El texto de Conrad resume las características y dificultades que supone la adopción de esta perspectiva de la historia global anglosajona para el estudio del pasado. Más interesante que el título de la traducción al castellano es el título original (What is global history?) ya que refleja mejor lo que el libro ofrece: un acercamiento a la historia global como concepto y enfoque histórico. La traducción del término global al castellano ya plantea dificultades al inducir alguna confusión. En el ámbito anglosajón la acepción "global" se refiere en primer lugar a su carácter geográfico, como conjunto del mundo, mientras que en segundo lugar se refiere a "global" como término que abarca la totalidad de algo. En castellano utilizamos dichas acepciones en el orden inverso, es decir, para nosotros el concepto global se entiende primero como algo tomado en su conjunto y después como referente al 
globo terráqueo. Este es un asunto importante, ya que, el vínculo entre el término "global" y el concepto de globalización parece más estrecho en inglés que en castellano.

Si definimos globalización como la incorporación de factores de producción (tierra, capital o trabajo) a un sistema económico que, previamente, debido a su lejanía geográfica no es posible explotar y que es la innovación técnica aplicada al transporte de mercancías, personas o información la llave que permite incorporar estos factores a dicho sistema económico, entonces, la historia global es la aceptación y naturalización de este fenómeno histórico y la adaptación del enfoque de los estudios históricos al mismo. Esta asunción de la globalización, no como un proceso histórico por definición cambiante y en flujo, sino como una realidad inmutable es apuntada por Conrad y en su trabajo se van desgranado algunas complicaciones asociadas a este enfoque de la historia global. Quizá la más notable de estas complicaciones ha sido la miopía a la hora de observar nuestro futuro más inmediato. Una miopía reconocible, por otra parte, en autores de otras épocas que, en momentos de cambios estructurales inminentes acabaron cegados por el sentido común dominante y no acertaron a ver lo evidente ${ }^{1}$.

A finales de los años setenta del pasado siglo Michel Foucault desarrolló un conjunto de herramientas conceptuales que nos permiten acercarnos a este fallo analítico con más precisión y claridad. Son los conceptos de "verdad" y de "régimen de veridicción" (Foucault, 2009). El uso de estas herramientas nos permite comprender mejor como lo que, durante un tiempo al menos, se consideró verdad (la globalización es un proceso histórico irreversible) y así fue asumido por la historia global no era más que el resultado de la construcción de un régimen de veridicción, un marco conceptual cuyos orígenes y características se pueden rastrear en el tiempo. Por tanto, más que una global history, en el sentido anglosajón, resultaría útil la construcción de una historia global, entendida como una historia de conjunto del marco conceptual que rige el mundo en el que vivimos y que, tal y como explicaba Foucault, establece qué es o no verdad.

Para comprender mejor los orígenes y características del marco conceptual (o régimen de veridicción) contemporáneo, asumido como natural por la historia global,

\footnotetext{
1 Un buen ejemplo de esa miopía ante la observación histórica, mencionado por el propio Conrad, es el de Stephan Zweig que de un modo muy vívido narra en su autobiografía El mundo de ayer las dificultades que tuvo su generación para comprender lo que estaba pasando en la Europa de los años previos al estallido de la I Guerra Mundial.
} 
es imprescindible la lectura el texto de I. Kant: Ideas para un Historia Cosmopolita Universal. En este texto se condensan, en unas pocas páginas, el proceso de racionalización y concreción de nuestro marco conceptual. Podemos reconocer con claridad todos los elementos característicos del mismo: el individualismo, la competencia, la idea de progreso como resultado de los anteriores y la expresión del convencimiento (o deseo) de que por naturaleza la especie humana caminaba hacia la constitución de un "Estado cosmopolita universal". Es esta una aportación germinal de lo que luego sería el concepto (y el deseo) de globalización. Las grandes depresiones económicas y las Guerras Mundiales de la primera mitad del siglo XX devaluaron las utópicas expectativas del relato ilustrado pero la caída del Muro de Berlín y el colapso de la URSS reverdecieron estas optimistas visiones cosmopolitas que, a continuación, fueron reactualizadas por $F$. Fukuyama y sus trabajos sobre el "fin de la Historia". Hay que añadir, por otra parte, que algunos aspectos del marco conceptual racionalizado y construido por autores varios y en momentos distintos (Hobbes, Locke, A. Smith o Kant a lo largo de los siglos XVII y XVIII) fueron revisados y actualizados por el liberalismo centroeuropeo a lo largo de los años cuarenta del pasado siglo. El régimen de veridicción liberal hoy dominante es el producto de una cultura con profundas raíces mercantiles y con un carácter fundamentalmente anglosajón. El relanzamiento del esfuerzo utópico liberal desde finales de los años sesenta y principios de los años setenta del pasado siglo se ha mantenido vigente hasta el estallido de la crisis económica de 2007 y 2008; desde entonces la distancia entre lo que las distintas utopías liberales prometían (un mundo de orden, equilibrio y crecimiento económico global) y sus resultados (una enorme crisis económica y financiera) ha desatado reacciones sociales y políticas en múltiples direcciones, entre ellas una fuerte corriente desglobalizadora que colisiona con el enfoque propuesto por la historia global.

Como podemos ver nuestro marco conceptual está compuesto de múltiples fragmentos de relatos que, a su vez, en algún momento tuvieron una vocación utópica o maquiavélica ${ }^{2}$ (o ambas a la vez). Hoy habitamos en escombros de utopías, cadenas de proyectos fallidos y sus resultados. Nos movemos y moveremos en un terreno confuso y esquivo. Un terreno en el que hechos y verdad pierden el compás. La verdad producto de nuestro marco conceptual se aleja de la capacidad

\footnotetext{
2 Con vocación maquiavélica nos referimos a la concepción, netamente liberal, de que "los sujetos de derecho sobre quienes se ejerce la soberanía política (...) [deben ser tratados] como una población que un gobierno debe manejar". (Foucault, 2009, p. 320)
} 
de explicar y anticipar hechos que finalmente están sucediendo y la historia global ha tenido un papel en ello.

\section{CRÍTICA DE LA HISTORIA GLOBAL}

Un primer acercamiento crítico a la historia global consiste en analizar las implicaciones de la elección del marco o escala temporal en el desarrollo de los estudios históricos y muestra como la naturalización de la globalización prioriza una visión inmovilizadora del largo recorrido temporal. Una visión que tiende a despolitizar la percepción de nuestras estructuras históricas, aquellas que, precisamente, sólo son visibles desde una perspectiva telescópica (Conrad, 2017). Esta ocultación ${ }^{3}$ de las estructuras históricas y de poder se combina con una visión microhistórica, fragmentaria, que construye relatos históricos generales a partir de una miríada de fragmentos que tiende a ensalzar el papel de lo individual y a ocultar la importancia de lo estructural. Al utilizar ambos marcos temporales en un mismo sentido la historia global anula las virtudes que resultan de combinar las visiones macro y micro históricas que no son otras que las de intentar acercarse, en lo posible, a la resolución de una aporía como es el vínculo entre lo individual y lo colectivo en el devenir histórico.

El hecho de que la historia global sea una corriente historiográfica básicamente anglosajona, tanto en lo que a instituciones académicas se refiere, como a la lengua en la que se producen sus trabajos abre otro flanco a la crítica. En mayo del pasado año se publicó una interesante entrevista al premio Nobel de literatura J. M. Coetzee; en respuesta a una de las preguntas decía:

(...) elegir no publicar en inglés era "un gesto", parte de su "distanciamiento" de un idioma en cuya visión del mundo no cree. "El peligro de que el inglés se convierta en un idioma global es que las opiniones que ese idioma tiene sobre el mundo también lo serán, y eso no es en absoluto bueno" (Coetzee, 2018).

En la respuesta del autor sudafricano se puede intuir la preocupación por que la extensión del inglés suponga, en paralelo, la extensión de una visión anglosajona del mundo; la extensión de lo que aquí hemos denominado un régimen de veridicción liberal o un marco conceptual mercantil. La historia global, como corriente

\footnotetext{
${ }^{3}$ El concepto de "agnotología" mencionado en el texto de Conrad y definido como "formas de no
} conocimiento inducidas culturalmente", resulta muy sugestivo. (Conrad, 2017) 
historiográfica, ha ejercido como amplificadora de esa extensión y, coincidiendo con Coetzee, eso no es en absoluto bueno.

Como decíamos el libro de Conrad es un texto útil y valioso a la hora de acercarnos a la historia global como corriente histórica y acierta a mostrarnos que, cuando como historiadores eludimos determinadas preguntas y naturalizamos las respuestas a las mismas, desenfocamos nuestros estudios y los hacemos más romos. Ahora bien, si deseamos profundizar en los aspectos solo esbozados por Conrad deberemos acudir a otros trabajos que abordan dichas preguntas de un modo más incisivo.

\section{¿PARA QUÉ UNA "NUEVA" hISTORIA GLOBAL?}

Pero lo que en estos tiempos produce angustia y náusea en las gentes sensibles no es sólo la permanencia y extensión del mal social y de la barbarie; es también, y sobre todo, la observación cotidiana de que la resistencia al mal o se siente impotente o está todavía sin columna vertebral. (Fernández Buey, 1995, p. 271)

Ante esta difícil perspectiva que se nos presenta deberíamos profundizar en algunos de los problemas, ya apuntados por Conrad, que plantea la historia global y, siguiendo otros trabajos, revisar algunas propuestas interesantes.

Sería más fructífero el uso de la primera acepción del término global en castellano y referirnos al mismo como algo tomado en su conjunto, desplazando el foco de lo espacial y vinculado al concepto de globalización y sustituirlo por una historia global, que busque analizar nuestro marco conceptual en su conjunto. Durante años, en lugar de pensar la globalización como un proceso histórico, como un elemento contextual, la pensamos como una realidad inmutable. Desde los años noventa hemos inmovilizado un escenario económico, social y político deseado por el dispositivo de poder liberal.

Una historia global debería, siguiendo las sugerentes y matizadas aportaciones de N. Chiaromonte, hacer las preguntas adecuadas. Una de las primeras cuestiones es la de volver al difícil equilibrio en la elección de la escala temporal y hacer posible una convivencia, siempre imperfecta, entre los enfoques u orientaciones micro y macro históricos (Guldi y Armitage, 2016, p. 213). Las relaciones entre lo individual y lo colectivo; entre los individuos y las grandes estructuras históricas y cómo estas, a 
su vez, están mediatizadas por eso que llamamos poder (Chiaramonte, 2018, p. 51). Una verdadera historia global debería afrontar estas preguntas 0 , al menos, si no disponemos de respuestas, hacerlas explícitas y compartir perplejidades. Omitirlas y dar respuestas que sabemos erróneas no puede ser un camino hacia el conocimiento histórico.

Otro trabajo muy crítico con la historia global, que plantea, dichas críticas de un modo más profundo y agudo que el texto de Conrad es el de Q. Slobodian: Globalists. The End of Empire and the Birth of Neoliberalism. Este autor hace ya una clara propuesta de trabajar por una historia global que intente explicar desde una perspectiva temporal una evolución del liberalismo y sus diferentes mutaciones; un estudio evolutivo que nos ayude a comprender mejor nuestra realidad presente. Slobodian defiende la necesidad de reorientar el enfoque de la disciplina histórica y que esta, a su vez, sea capaz de evitar la extracción de lo político del marco conceptual. El objetivo debería ser desarrollar una herramienta que permitiera superar las racionalizaciones contractualistas que desde Locke a Rawls han visto a la sociedad como producto de un acto individual y racional. Estas poderosas racionalizaciones están en el núcleo de las miopías, de los fallos de análisis, propios de la historia global que criticamos.

Mucho nos tememos que la quiebra, que el abismo conceptual ante el que nos encontramos es el equivalente a un fin de era, un momento en el que el tronco común de las dos grandes corrientes ideológicas y políticas que dominaron la segunda mitad del siglo $\mathrm{XX}$ se ha descompuesto desde dentro. Liberalismo y comunismo han implosionado en fechas cercanas desde un punto de vista histórico; si los años 1989 y 1991 marcaron el declive del comunismo, 2007 y 2008 han supuesto la crisis de los presupuestos liberales. En estos momentos de expectativas defraudadas, de frustración y de tensión social en aumento la distancia entre "verdad" y "realidad" no hace más que aumentar. La realidad se aleja progresivamente de la verdad dada por nuestro marco conceptual. Nuestras herramientas conceptuales están, después de años de hibernación de la política, claramente anquilosadas. Las opciones en las circunstancias actuales no son muchas: o somos capaces de modificar el marco conceptual contemporáneo a través de procesos de reforma o las soluciones a nuestros problemas se buscarán en una profundización del marco conceptual mercantil. Este proceso ya ha comenzado en muchos lugares, España entre ellos. Dicha profundización se 
produce en torno a principios y valores ya existentes en el marco conceptual liberal: un individualismo feroz, una visión biologicista del mundo social y político, en la que el progreso se produce a través de una competencia no ya comercial, sino por la vida misma... una tendencia, en síntesis, a deslizarse hacia el autoritarismo. El origen de esta tendencia no es otro que el mostrado por Chiaromonte cuando escribe:

La convicción de que existía una armonía preestablecida entre el orden del mundo y las esperanzas del hombre, en que ambos eran parte del mismo proceso cósmico de evolución, en una palabra, la convicción de que la historia natural y la humana eran partes integrales la una de la otra, estaban en armonía y constituían una realidad única cuyas leyes descubría la razón experimental y aplicaba la razón práctica. (...) Con todo, la pregunta “¿por qué?” sigue sin respuesta y el progreso, la "superación" y la obediencia a la oscura fuerza de las leyes biológicas se convierten en fines inmotivados e implacables. (Chiaromonte, 2018, p. 208)

El peligro radica en que esta "versión profunda", que subyace en nuestro marco conceptual liberal, dulcificada por las versiones más humanizadas que acostumbramos a contarnos, emerja, y que versión profunda y sentido común popular se igualen. ${ }^{4}$ En el caso de España la constante identificación que los representantes del partido político de ultraderecha VOX hacen de sus propuestas con el sentido común es una muestra de que, dichos representantes, pretenden hacer emerger esta versión profunda y poco amable de los principios liberales y convertirla en dominante. ${ }^{5}$

Deberíamos retomar las advertencias ya lanzadas por la Escuela de Fráncfort y reinterpretar conceptos como razón, progreso o derechos civiles (Pasolini, 2017, p. 169) y hacerlo de forma cuidadosa ya que nos encontramos en una peligrosa posición, desde la que el deslizamiento hacia la extrema derecha es fácil y puede resultar inadvertido.

En estos momentos críticos el papel de una "nueva" historia global debería ser desarrollar una herramienta, un instrumento de análisis y crítica de nuestros marcos

\footnotetext{
${ }^{4}$ Las Cartas Luteranas de Pasolini son una expresión anticipadora de una "mutación cultural" cuyos efectos más agudos estallan hoy ante nuestros ojos (Pasolini, 2017).

${ }^{5}$ Sólo a modo de ejemplo: Vox: El sentido común... (2019). no entiende de etiquetas". La Vanguardia 10 de noviembre de 2019.
} 
conceptuales. Una herramienta que nos permita contextualizar y estudiar los mismos en su desarrollo temporal. Una propuesta que cuide el vínculo entre microscopía y telescopía histórica. Estas propuestas deberían ayudarnos, no a asumir verdades, sino a comprender mejor por qué consideramos "verdad" cosas distintas en distintos momentos históricos.

Los peligros inherentes a estos planteamientos son muchos: la falta de pie analítico, el relativismo o el vaciamiento en la generalización del contenido..., de todos modos, la urgencia del momento invita a intentar resolverlos mientras se vayan presentando, siendo conscientes, además, de su imposible resolución completa.

Necesitamos una historia global que nos ayude a decidir qué conservar de nuestro fallido marco conceptual. Que nos ayude, a través de estudios históricos globales bien fundamentados, a "dotar a la resistencia ante lo que se avecina de una columna vertebral" (Fernández Buey, 1995).

\section{REFERENCIAS}

Coetzee (2018, enero 29). No me gusta que el inglés se haya apoderado del mundo. El País. Recuperado de: https://n9.cl/n07c

Conrad, S. (2017). Historia global. Una nueva visión para el mundo actual. Barcelona: Crítica.

Chiaromonte, N. (2018). La paradoja de la historia. Cinco lecturas sobre el progreso: de Stendhal a Pasternak. Barcelona: El Acantilado.

Fernández Buey, F. (1995). La barbarie de ellos y de los nuestros. Barcelona: Paidos.

Foucault, M. (2005). Nacimiento de la biopolítica. Madrid: Akal.

Guldi, J. y Armitage, D. (2016). Manifiesto por la historia. Madrid: Alianza.

Kant, I. (2010). Ideas para una historia universal en clave cosmopolita y otros escritos sobre Filosofía de la Historia. Madrid: Tecnos.

Pasolini, P. (2017). Cartas luteranas. Madrid: Trotta.

Roldán, C. (2005). Entre Casandra y Clío. Una historia de la filosofía de la Historia. Madrid: Akal.

Slobodian, Q. (2018). Globalists. The End of Empire and the Birth of Neoliberalism. Londres: Harvard University Prees. 
Juan Seoane, Lo que la historia global es y lo que...

Vox: El sentido común no entiende de etiquetas. (2019, noviembre 10). La Vanguardia. Recuperado de: https://n9.cl/bk6z 